\title{
A new double-purpose device for elbow extension in tetraplegia with paralysis below $\mathrm{C5}$
}

\author{
M Itzkovich Otr, ${ }^{1,2}$ A Catz MD, ${ }^{1,2,3}{\text { I Ona } \mathrm{CPO}^{4}}^{4}$ \\ ${ }^{1}$ Loewenstein Rehabilitation Hospital, PO Box 3, Raanana 43100; ${ }^{2}$ Sackler Faculty of \\ Medicine, Tel-Aviv University, Tel-Aviv; ${ }^{3}$ IDF Medical Corps; ${ }^{4}$ Gapim Ltd-Loewenstein \\ Hospital branch, Israel.
}

\begin{abstract}
A new device for elbow extension, developed as a dynamic orthosis and also as a static splint for a C5 tetraplegic arm, is presented. A patient with tetraplegia, probably related to infection of the central and peripheral nervous system, had a paralysed right triceps muscle, with a very strong corresponding biceps. Extension by force of a posterior stretched rubber ring made the arm useful, while the possibility to lock the elbow hinges of the orthosis at any desired angle enabled static splinting of the elbow to increase the range of motion.
\end{abstract}

Keywords: tetraplegia; flexion contracture; orthosis; dynamic splint.

\section{Introduction}

Flexion contracture of the elbow is a well known complication of spinal lesions below the C5 segment which may aggravate the disability of the tetraplegic patient. ${ }^{1}$ This contracture is caused by overactivity of the forearm flexors which is not balanced by the paralysed triceps.

Guttmann $^{1}$ pointed out the importance of avoiding permanent forearm flexion in patients with this type of lesion in order to prevent contracture. The methods used for this purpose include elbow extension by various splints. ${ }^{2-7}$ Among these are static splints, which maintain correct joint alignment and range of motion (ROM), and dynamic splints, which mobilize joints, provide passive traction to the musculotendinous tissue over an extended period of time and improve function. ${ }^{8}$ Properties of both types of splints have to be combined in one device to achieve two objectives simultaneously: improve the active ROM at the elbow (the amount of motion achieved at the joint when the patient uses his own muscle power) and enable purposeful function of the paralysed limb. Such a combined static and dynamic splint was developed for a tetraplegic patient with paralysis of the right arm below the $\mathrm{C} 5$ level and is presented here.

Correspondence: Dr Catz.

\section{The splint}

The orthosis comprises arm and forearm braces made of polyethylene and shaped to fit the patient's upper limb; it is attached to the limb by means of Velcro straps (Fig $1 \mathrm{a} \& \mathrm{~b})$. The two pieces are connected by flail arm hinges, with one side locking (FAH-100, Hosmer Durrance Corp). The hinges are parallel and in line with the medial and lateral epicondyles of the elbow (Fig $1 \mathrm{~b} \& \mathrm{c}$ ). The dynamic mechanism of the splint is based mainly on the force exerted by a rubber ring extension assist (Otto Bock $619 \mathrm{R} 4)$ on the posterior aspect of each of the braces (Fig 1c). A spring connected to the arms of the medial hinge assists starting elbow extension from full flexion (Fig 1b). For static activity the splint can be locked by pulling a string connected to the locking mechanism which is attached to the lateral hinge. The elbow may be locked at any desired angle and released by an additional pull of the string.

\section{Case report}

A 67 year old patient was transferred to the Loewenstein Rehabilitation Hospital with tetraplegia of 6 weeks' duration, after evaluation and treatment at a general teaching hospital. The neurological disorder had developed following a febrile illness, probably caused by a herpes virus. It involved both the spinal cord 
a

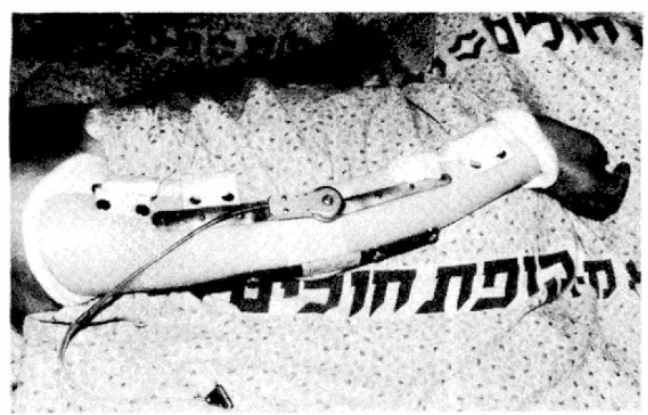

b

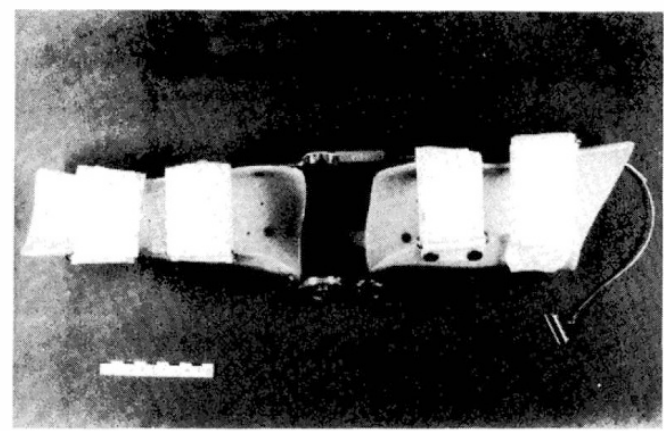

c

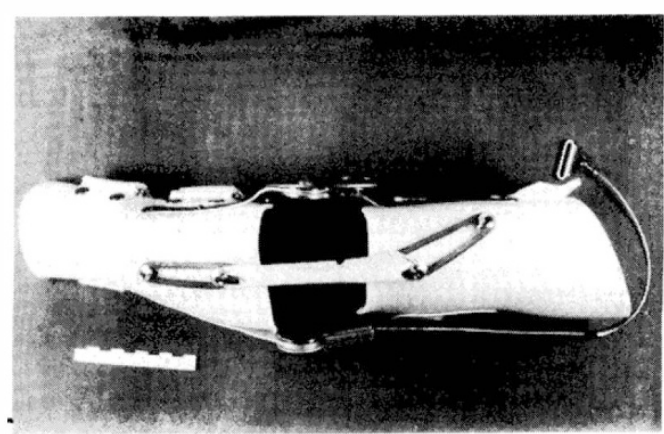

Figure 1 The double-purpose elbow extension orthosis (a) lateral view, (b) antero-medial view, (c) posterior view.

and peripheral nerves. On admission to the spinal rehabilitation ward, the patient had no movements in the left upper limb. In the right upper limb the triceps muscle was paralysed, but the deltoid was effective and the biceps was strong. Some movements could also be noted in the right hand. The trunk and lower limbs were completely paralysed. Sensation was reduced below the C4 level and absent below T4. Muscle tone was flaccid and no tendon reflexes could be elicited. The patient had no sphinct- eric control. Within a few weeks an extensor plantar reflex appeared, and some movements were noted in the left upper limb, mainly of the triceps and extensor digitorum muscles. This limb, however, was not useful. The right upper limb was stronger, but in spite of daily passive stretching, the biceps had shortened, and flexion contracture was imminent. When the patient lay supine, the flexed limb was powerfully pulled towards the face or neck and he could not lift it. In the sitting position, the shortening of the biceps prevented useful activity of the right hand.

The orthotic device described above enabled useful and comfortable function of the limb in the supine and sitting positions. Using the device with the hinges unlocked, the patient could bring his hand to any part of his face and head and move it away when he desired. When the lateral hinge was locked, he used the device as a static splint. The locking mechanism was handled by an attendant. Within 2 weeks of employing the splint, passive extension of the right elbow became much easier. As extension became possible by gravity alone, the patient started using his arm successfully in the sitting position even without the orthosis.

\section{Discussion}

Patients with spinal lesions below the C5 segment have intact shoulder movements and elbow flexion that may enable purposeful activities. Paralysis of the triceps, however, exposes these patients to the risk of developing flexion contractures of the elbows which restrict their ability to position the hands. ${ }^{1}$ Maintenance of full ROM with prevention of contracture is, therefore, an important goal included in the rehabilitation programme for these patients. The main conventional therapeutic measure for improving ROM is manual passive stretching. ${ }^{9}$ Orthotic devices, however, may add prolonged gentle stretch, which has also been recognised as an effective method for ROM restoration. ${ }^{4,9,10}$ A few elbow extension orthoses have been described in the literature. They include the Turnbuckle Splint ${ }^{5}$ the Wire Foam Elbow Extension Splint ${ }^{4}$ and the Dynasplint, ${ }^{6}$ which seem to be useful in cases of rigid elbow contractures that need a gradual increase in ROM. They also include the Pronator Lively Splint of Abrahams et al, ${ }^{7}$ a dynamic functional 
orthosis which provides forearm pronation and elbow extension.

All these splints, however, were found inappropriate for our patient. This patient did not have rigid contracture; elbow extension could be achieved by passive stretching through full ROM. On the other hand, the flexion tendency of his elbow did not allow extension by gravity, and a strong external power was required to overcome it and enable improvement in active ROM. The static splints described lacked the flexibility needed for function, while a spring mechanism similar to that described by Abrahams et $a l^{7}$ was not strong enough to overcome the elbow flexion through the full ROM.
The combination of a hinge spring and a strong posterior rubber band with a locking mechanism enabled the patient to alternate useful function and passive stretching.

The case presented demonstrates the possibility of improving results by combining customary therapeutic measures. In our case, the combination of static and dynamic mechanisms in a single orthosis improved the functional activity of an upper extremity in a tetraplegic patient.

\section{Acknowledgement}

We would like to thank Gapim Ltd-Israel Orthopedic Industry for supporting this work.

\section{References}

1 Guttmann L (1976) Symptomatology. In: Spinal Cord Injuries: Comprehensive Management and Research. Blackwell Scientific Publications, Oxford: 260-279.

2 Bender LF (1990) Upper extremity orthotics. In: Kottke FJ, Lehmann JF, editors. Krusens' Handbook of Physical Medicine and Rehabilitation. W B Saunders Company, Philadelphia: 580-592.

3 Ragnarsson KT (1988) Orthotics and shoes. In: DeLisa JA, editor. Rehabilitation Medicine: Principles and Practice. J B Lippincott, Philadelphia: 307-329.

4 Trombly CA (1989) Orthoses: Purposes and types. In: Trombly CA, editor. Occupational Therapy for Physical Dysfunction. Williams and Wilkins, Baltimore: 329-355.

5 Green DP, McCoy H (1979) Turnbuckle orthotic correction of elbow flexion contractures after acute injuries. J Bone Joint Surg 617: 1092-1095.

6 Hepburn GR, Crivelli KJ (1984) Use of elbow Dynasplint for reduction of elbow flexion contracture: a case study. J Orthop Sports Physical Ther 5: 269-274.

7 Abrahams D, Shrosbree RD, Key AG (1979-80) A functional splint for the C5 tetraplegic arm. Paraplegia 17: 198-203.

8 Duncan RM (1989) Basic principles of splinting the hand. Phys Ther 69: 1104-1116.

9 Mackay-Lyons M (1989) Low-load prolonged stretch in treatment of elbow-flexion contractures secondary to head-trauma: a case report. Phys Ther 69: 292-296.

10 Kottke FJ, Pauley DL, Ptak RA (1966) The rationale for prolonged stretching for correction of shortening of connective tissue. Arch Phys Med Rehabil 47: 345-352. 